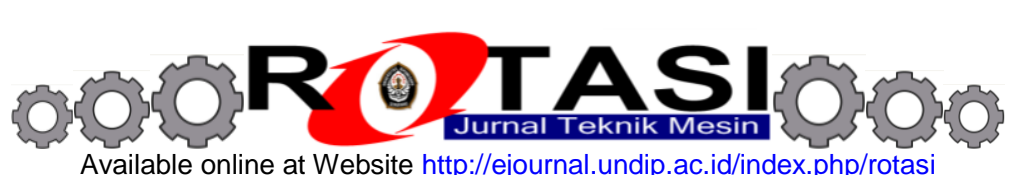

\title{
ANALISIS NUMERIK DAN VALIDASI KASUS KAVITASI POMPA SENTRIFUGAL MISSION MAGNUM I MENGGUNAKAN CFD
}

\author{
*Eflita Yohana ${ }^{\mathrm{a}}$, M.Fandiar Majiid ${ }^{\mathrm{b}}$ \\ ${ }^{a}$ Dosen Departemen Teknik Mesin, Fakultas Teknik, Universitas Diponegoro \\ ${ }^{b}$ Mahasiswa Departemen Teknik Mesin, Fakultas Teknik, Universitas Diponegoro \\ Jl. Prof. H. Soedarto, SH, Tembalang-Semarang 50275, Telp. +62247460059 \\ *Email: efnan2003@gmail.com
}

\begin{abstract}
ABSTRAK
Salah satu penyebab menurunnya performa pompa adalah kavitasi. Kavitasi pada pompa sentrifugal dapat menimbulkan efek kerugian yang sangat buruk seperti turunnya performa pompa yang disebabkan erosi, getaran, dan kebisingan yang terjadi. Kavitasi dapat terjadi dalam kondisi apapun, untuk mencegahnya kita harus mengetahui fenomena awal kavitasi pada pompa. Untuk mendeteksi kavitasi kita bisa menggunakan berbagai macam metode atau software, salah satunya dengan CFD (Computational Fluid Dynamic) dan metode FVM (Finite Volume Methode) yang sudah di validasi terlebih dahulu. Percobaan yang telah dilakukan memperoleh tekanan absolut yang sangat rendah pada bagian sisi isap pompa mencapai $2650 \mathrm{~Pa}$. Hal tersebut bisa menjadi dasar indikasi terjadinya kavitasi.
\end{abstract}

Kata kunci: kavitasi, FVM ,tekanan absolut

\section{PENDAHULUAN}

Pompa merupakan salah satu mesin aliran fluida hidrolik yang berfungsi untuk memindahkan fluida tak mampat (incompressible fluids) dari suatu tempat ke tempat lain dengan cara menaikkan tekanan fluida yang dipindahkan tersebut. Pompa juga merupakan mesin yang mengkonversikan energi mekanik menjadi energi tekanan. Pompa akan memberikan energi mekanis pada fluida, dan energi yang diterima fluida berguna menaikkan tekanan pada saluransaluran instalasi pompa.

Pompa sentrifugal termasuk jenis pompa rotary yang mengembangkan tekanan dinamis sehingga dapat memindah fluida dari tempat rendah ke tempat lebih tinggi [1]. Pompa sentrifugal telah banyak dipakai oleh industri terutama pengolahan dan pendistribusian fluida bekerja dengan prinsip putaran impeller sebagai elemen pemindah fluida yang digerakkan oleh suatu penggerak mula. Zat cair akan berputar akibat dorongan sudu-sudu dan menimbulkan gaya sentrifugal yang menyebabkan cairan mengalir dari tengah impeller dan keluar melalui saluran sudusudu dan meninggalkan impeller dengan kecepatan tinggi. Cairan dengan kecepatan tinggi ini dilewatkan saluran yang penampangnya makin membesar sehingga terjadi perubahan head (tinggi tekan) kecepatan menjadi head tekanan. Setelah cairan dilemparkan oleh impeller, ruang diantara sudu-sudu menjadi vacuum, menyebabkan cairan akan terhisap masuk sehingga terjadi proses pengisapan [2].

Turunnya performansi pompa secara tiba-tiba dan ketidakstabilan dalam operasi akan menjadi masalah, indikasi penyebab turunnya performansi pompa salah satunya disebabkan oleh kavitasi. Kavitasi terjadi akibat rendahnya tekanan pada sisi hisap sampai dibawah tekanan uap jenuhnya sehingga terjadi perubahan fasa dari zat cair menjadi uap dan menimbulkan gelembung-gelembung udara. Fenomema ini sangat berbahaya dan diketahui sebagai fenomena yang bersifat merusak pada bagian-bagian penting instrumen pompa dan menurunkan performansi dari pompa itu sendiri. Dalam hal ini bagian pompa yang sering mengalami kavitasi adalah sisi isap pompa.

Penelitian terhadap kavitasi dengan melakukan pengamatan terjadinya kavitasi dan getaran yang ditimbulkan dengan menganalisa distribusi tekanan dan tekanan uap jenuh pada impeler secara numerik dengan menggunakan Finite Volume Methode (FVM). Dengan dilakukannya simulasi peristiwa terjadinya kavitasi di didaerah impeler pompa dapat diketahui dengan melihat distribusi tekanan yang terjadi pada daerah impeler.

Tujuan dari penelitian ini adalah untuk mendapatkan hasil analisis numerik beserta grafik kasus sebelum terjadi kavitasi dan setelah kavitasi, dan juga membuktikan rendahnya nilai tekanan absolut pada bagian suction.

\section{STUDI LITERATUR}

Penelitian dan Pengujian terhadap kavitasi pada pompa sangat menarik sehingga telah banyak dilakukan oleh beberapa peneliti dan balai pengujian untuk menguji dan beberapa beberapa penyebab dari aspek yang berbeda diantaranya adalah : yang mendeteksi kavitasi dimana eksperimen dilakukan pada sebuah pompa sentrifugal, fenomena kavitasi di deteksi dengan pemantauan tekanan masuk dinamik pada inlet [3]. Penelitian ini dapat dijadikan indikasi awal terjadinya kavitasi pada pompa dengan munculnya suara bising dan metode ini bisa digunakan untuk mengetahui keausan ring (seal). Selanjutnya kajian terhadap gejala-gejala yang muncul terhadap proses terjadinya kavitasi, penelitian ini memaparkan parameter yang terdiri dari suara berisik, getaran, turunnya performansi dan terjadinya 
kerusakan impeller sebagai akibat terjadinya kavitasi [4]. Berikutnya tentang pengaruh tekanan dan temperatur terhadap kavitasi. Penelitian ini menggambarkan adanya pengaruh tekanan dan temperature [5].

\section{MATERIAL DAN METODOLOGI}

Untuk mendapatkan hasil dari tujuan-tujuan pada kasus ini dilakukan analisis untuk mensimulasikan fenomena kavitasi kemudian membandingkan dengan tekanan uap jenuh yaitu $2650 \mathrm{~Pa}$. Pada penelitian ini diberikan batasanbatasan masalah dan asumsi sebagai berikut: Persamaan Navier-Stroke sebagai persamaan dasar, dan di sederhanakan dengan persamaan kontinuitas, fluida yang mengalir dianggap fully developed, volume dianggap konstan. Pada proses simulasi dibatasi dengan persamaan pembentuk aliran (governing equations) [6].

1. Persamaan kontinuitas

$$
\frac{\partial u}{\partial x}+\frac{\partial u}{\partial y}=0
$$

2. Persamaan momentum

$$
\begin{aligned}
& u \frac{\partial u}{\partial x}+v \frac{\partial u}{\partial y}=-\frac{\partial p}{\partial x}+\mu\left(\frac{\partial^{2} u}{\partial x^{2}}+\frac{\partial^{2} u}{\partial y^{2}}\right) \\
& u \frac{\partial v}{\partial x}+v \frac{\partial v}{\partial y}=-\frac{\partial p}{\partial y}+\mu\left(\frac{\partial^{2} v}{\partial x^{2}}+\frac{\partial^{2} v}{\partial y^{2}}\right)
\end{aligned}
$$

3. Persmaan energi

$$
u \frac{\partial T}{\partial x}+v \frac{\partial T}{\partial y}=-\frac{k}{\rho c_{p}}+\left(\frac{\partial^{2} T}{\partial x^{2}}+\frac{\partial^{2} T}{\partial y^{2}}\right)
$$

Setelah melalui tahap validasi dengan jurnal "Computational Fluid Dynamics (CFD) of Centrifugal Pump to Study the Cavitation Effect" didapat nilai galat $12 \%$ selanjutnya proses analisis CFD, terutama fluida dan sifat aliran dapat mempengaruhi performa sistem pompa. Langkah untuk analisis CFD menggunakan Finite Volume Methode $(F V M)$ dapat dilakukan dengan cara dibawah ini:

\subsection{Tahap pre-processing}

Pada tahap ini, membuat model CAD bisa menggunakan berbagai macam software misalnya Solidwork, catia, inventor, dan lain-lain. Selanjutnya pengaturan fluida dan daerah aliran dilakukan di ANSYS-CFX. Pada contoh kasus ini pompa memiliki kecepatan sudut sebesar $2160 \mathrm{rev} / \mathrm{min}$, dan tekanan relative di asumsikan sebesar $600 \mathrm{Kpa}$. Gambar 1 dibawah merupakan hasil dari CAD sedangkan Gambar 2 sketsa dari CAD impeler yang telah diberi kondisi batas.

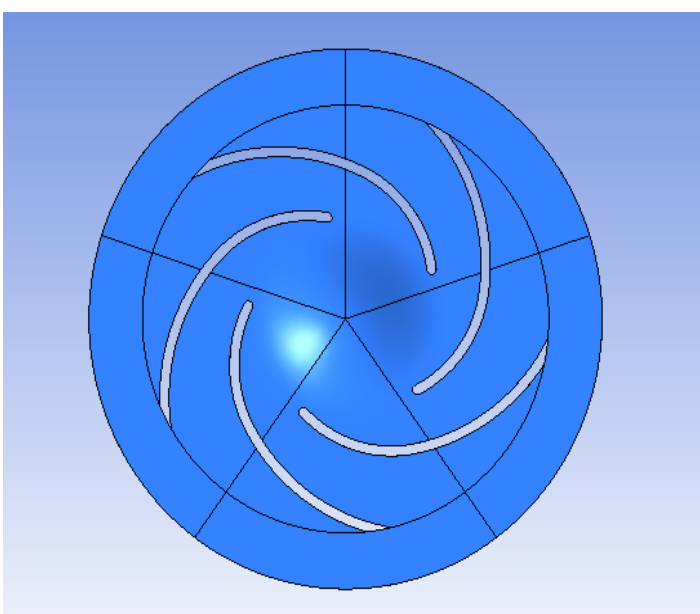

Gambar 1. model CAD

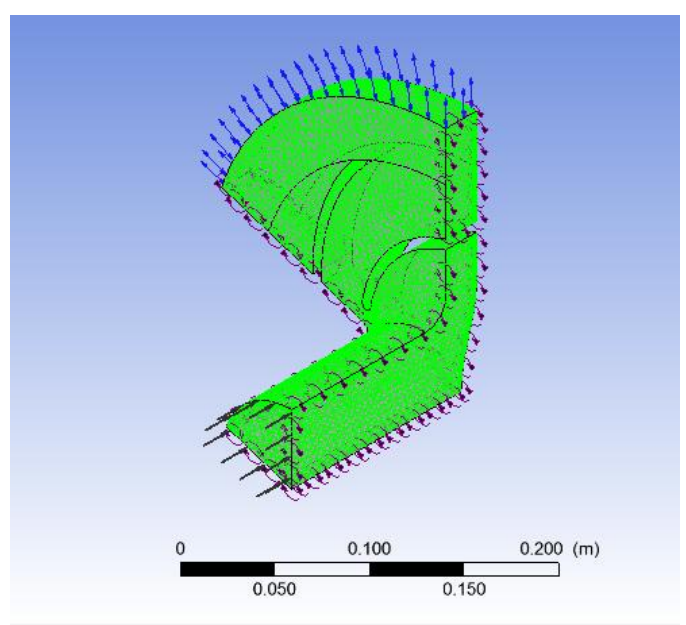

Gambar 2. Kondisi batas

\subsection{Tahap processing}

Pada model kavitasi ini mengikuti model turbulen untuk merencanakan distribusi tekanan pada system pompa sentrifugal. Model ini memiliki beberapa karakteristik:

1) Aliran turbulen konsisten terhadap bentuk fisik

2) Akurasi prediksi cukup teliti

3) Memberikan performa yang unggul untuk aliran yang berotasi 
Berikut dibawah ini merupakan gambar dari tahap processing.

\subsection{Tahap post-processing}

Pada tahap analisis CFD, berikut hal yang perlu dilakukan:

1) Menginterpretasikan hasil analisis

2) Memberikan distribusi tekanan pada daerah blade dan shroud pompa sentrifugal

\section{HASIL DAN PEMBAHASAN}

Pada studi kasus tentang kavitasi pompa sentrifugal, dengan maksud untuk menyelidiki efek 5 blades terhadap kavitasi pompa sentrifgual. Dalam tahap ini didapat hasil iterasi dari data eksperimen dan data lapangan menggunakan Finite Volume Methode (FVM). Tahap awal dari proses analisa ini ada hasil iterasi dari pompa sebelum mengalami kavitasi dan sudah mengalami, gambar-gambar dibawah ini merupakan hasil iterasi data eksperimen yang telah di validasi dan data lapangan sebagai berikut:

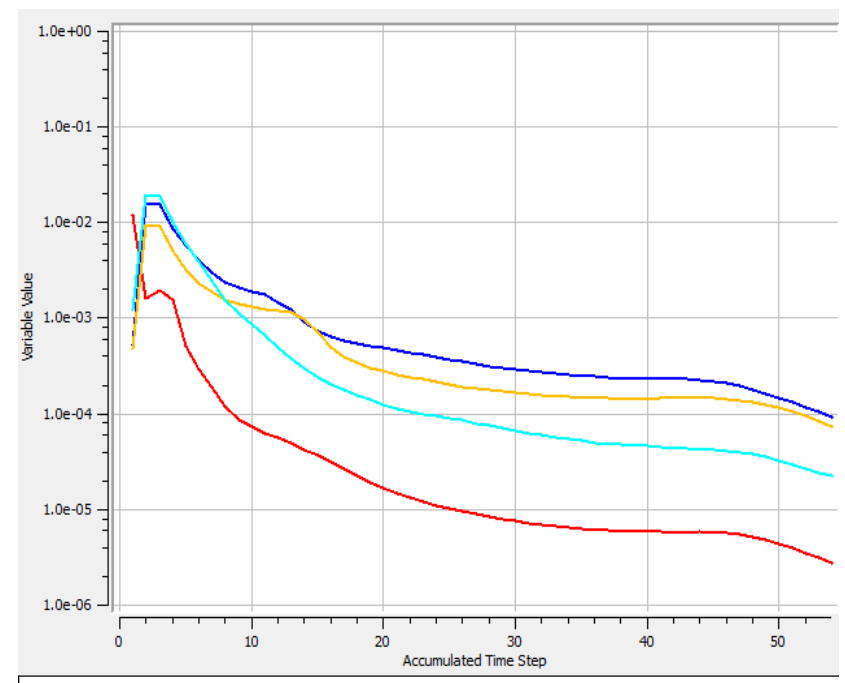

Gambar 3. Data eksperimen sebelum kavitasi

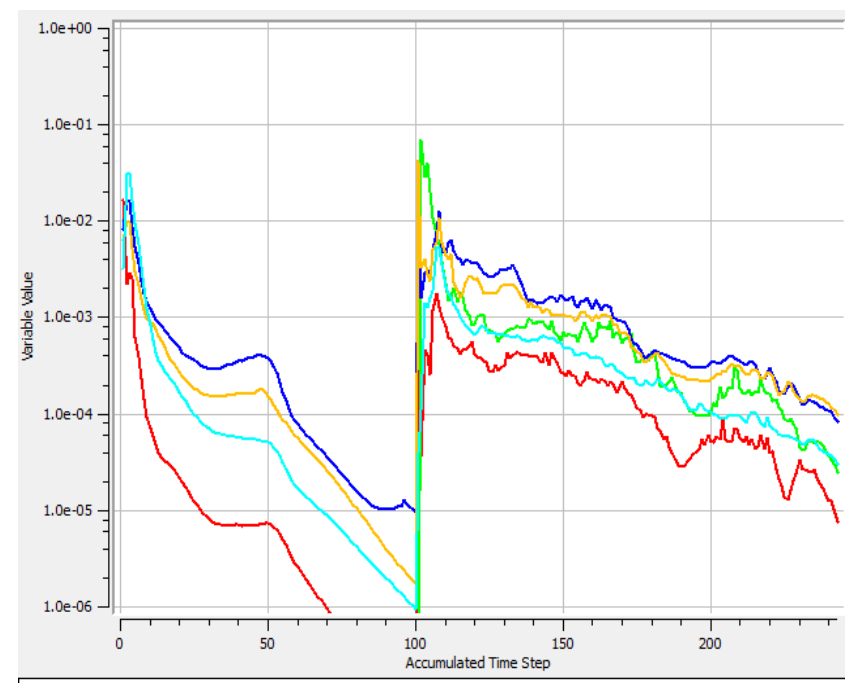

Gambar 5. Data eksperimen setelah kavitasi

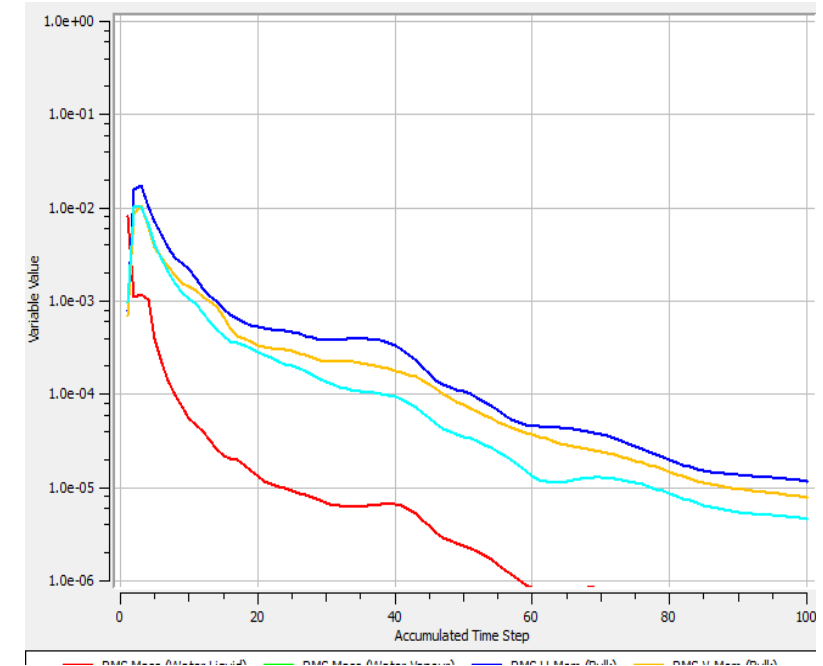

Gambar 4. Data lapangan sebelum kavitasi

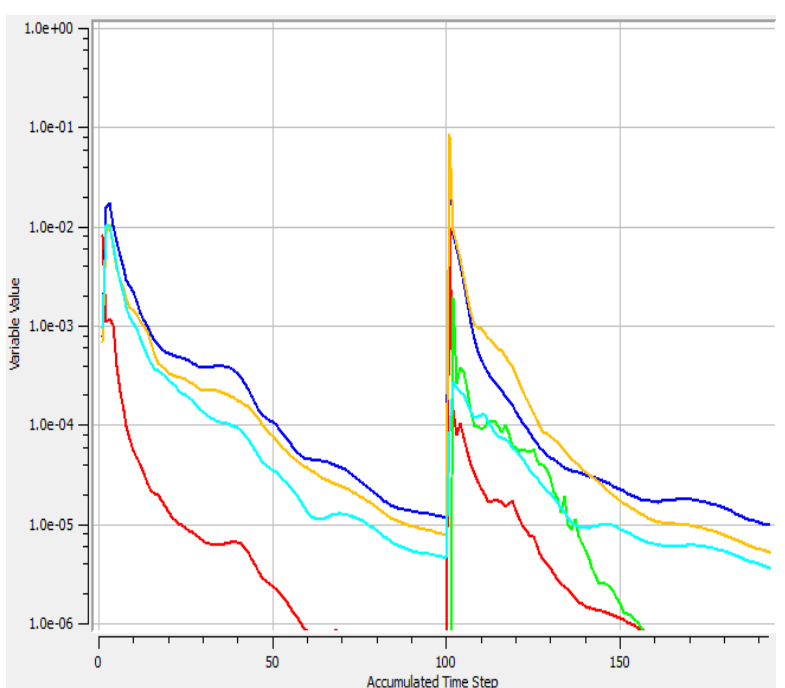

Gambar 6. Data lapangan setelah kavitasi

Dari Gambar 3-4 dan Gambar 5-6 diatas terlihat ada nya perbedaan, grafik pada saat kavitasi terjadi lonjakan spike dibandingkan grafik yang tidak mengalami kavitasi. Selanjutnya dari hasil iterasi di atas kita bisa mendapatkan distribusi tekanan pada blade baik sebelum kavitasi maupun sudah mengalami kavitasi. Gambar 7-10 dibawah ini merupakan gambar distribusi tekanan pada blade. 


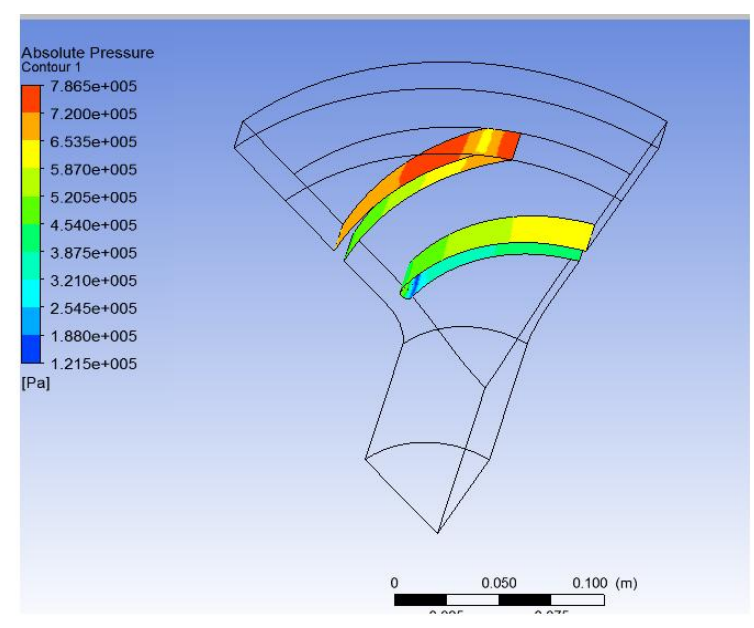

Gambar 7. Blade sebelum kavitasi (eksperimen)

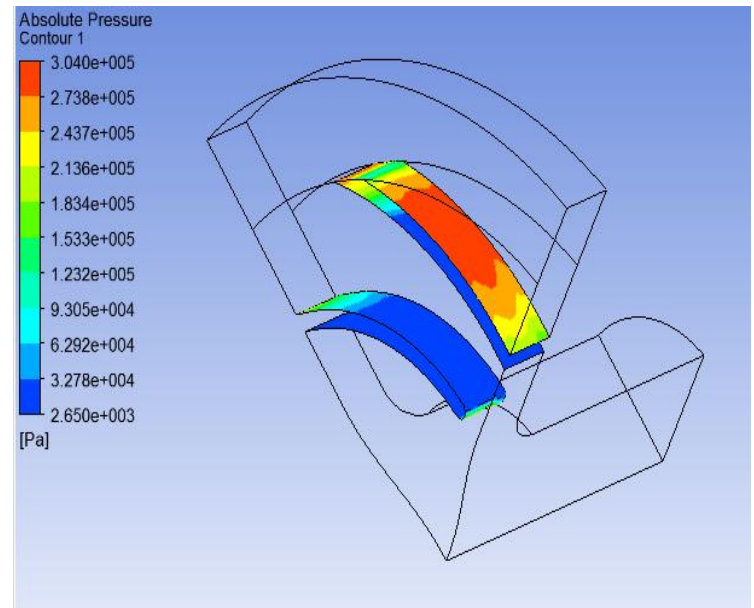

Gambar 9. Blade setelah kavitasi (eksperimen)

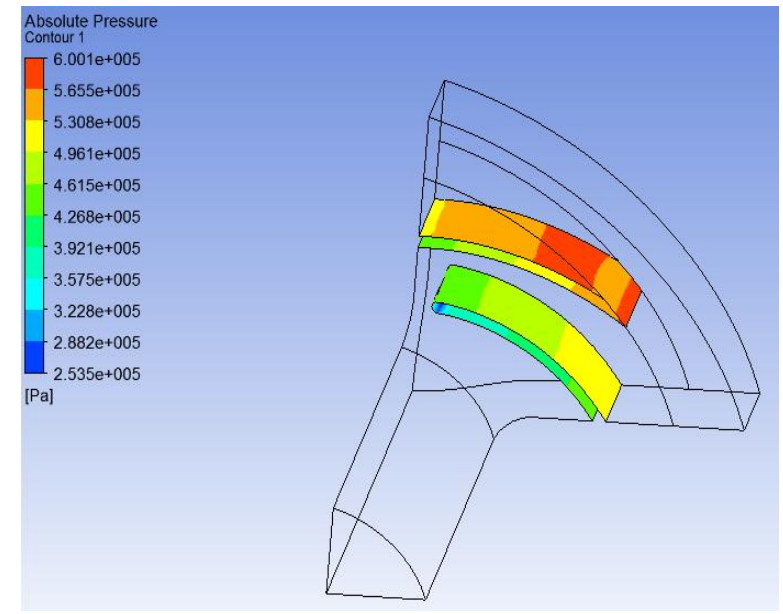

Gambar 8. Blade sebelum kavitasi (lapangan)

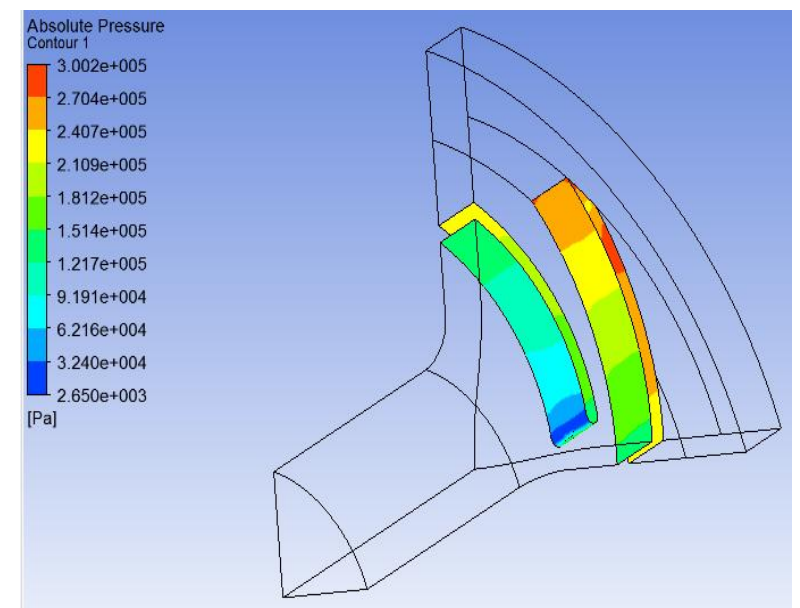

Gambar 10. Blade setelah kavitasi (lapangan)

Setelah memodifikasi fisik dari suatu model kavitasi kita dapat melihat perbedaan secara jelas dari distribusi tekanan pada blade. Gambar 7 dan Gambar 8 menunjukkan nilai tekanan absolut minimum masih diatas 100.000 Pa, sedangkan gambar 9 dan gambar 10 menunjukkan tekanan absolut minimum sebesar $2650 \mathrm{~Pa}$. Rendahnya nilai tekanan absolut itu yang menjadi indikasi timbulnya gelembung-gelembung dan penyebab terjadinya kavitasi.

\section{KESIMPULAN}

Dari hasil simulasi, diketahui tekanan absolut terendah pada daerah impeler sebelum mengalami kavitasi sebesar 121.500 - 253.500 Pa, dengan nilai tekanan absolut sebesar itu perubahan fasa cair menjadi uap pada sisi isap belum menimbulkan gelembung. Kemudian hasil simulasi saat setelah terjadi kavitas nilai tekanan absolut terendah adalah 2650, dengan rendahnya tekanan absolut tersebut gelembung-gelembung timbul dengan sangat cepat sehingga menjadi penyebab terjadinya kavitasi.

\section{REFERENSI}

[1] Suhane, A., 2012, "Experimental Study on Centrifugal Pump to Determine the Effect of Radial Clearance on Pressure Pulsations, Vibrations and Noise,",IJERA,Vol. 2, Issue4, ISSN: 2248-9622, pp.1823-1829.

[2] Ungkawa, U., 2010, "Pompa Dan Kompressor," Bandung.

[3] Jeremy, J., Kenwood, D., 2000,'Experimental Results of the Pump Laboratory Detecting Cavitation in Centrifugal Pumps: Detecting Cavitation in Centrifugal Pumps, ".

[4] Hanandoko,T.B., 2000, "Deteksi Instalasi Pompa Sentrifugal Terhadap Gejala Kavitasi,". Jurnal Teknologi Industri Vol.IV.

[5] Gultom, D., 2001, "Studi Eksperimen Pengaruh Tekanan dan Temperatur pada Kavitasi,", Teknik Mesin Institut Teknologi Sepuluh Nopember.

[6] Ambarita, H., 2011, "Internal Flow Forced Convection,",Sustainable Energy Research Group Mechanical Engineering Universitas Sumatera Utara. 